\title{
2230. Effect of vibroacoustic therapy on pain management in adolescents with low back pain
}

\author{
Vilma Dudoniene ${ }^{1}$, Lina Varniene ${ }^{2}$, Tomas Aukstikalnis ${ }^{3}$, Egle Lendraitiene ${ }^{4}$, Justas \\ Cerkauskas $^{5}$, Juozas Raistenskis ${ }^{6}$ \\ ${ }^{1}$ Lithuanian Sports University, Sporto g. 6, LT-44221 Kaunas, Lithuania \\ ${ }^{2,}{ }^{6}$ Faculty of Medicine, Vilnius University, Vilnius, Lithuania \\ $2,3,{ }^{6}$ Children Hospital, Affiliate of Vilnius University Santariskiu Clinics, \\ Santariškių st. 7, LT- Vilnius, Lithuania \\ ${ }^{4}$ Lithuanian University of Health Science, Department of Rehabilitation, \\ Eivenių g. 2, LT 50009 Kaunas, Lithuania \\ ${ }^{5}$ Research Institute of Internet and Intelligent Technologies, Vilnius Gediminas Technical University, \\ Sauletekio al. 11, 10223 Vilnius, Lithuania \\ ${ }^{1}$ Corresponding author \\ E-mail: ${ }^{1}$ vilma.dudoniene@gmail.com, ${ }^{2}$ linautnlinautn@gmail.com, ${ }^{3}$ aukstikalnis@gmail.com, \\ 4egle_77@yahoo.com, ${ }^{5}$ justas.cerkauskas@gmail.com, ${ }^{6}$ jraist@vuvl.lt \\ Received 14 May 2016; received in revised form 26 September 2016; accepted 27 September 2016 \\ DOI https://doi.org/10.21595/jve.2016.17165
}

\begin{abstract}
Vibroacoustic Therapy (VT) is a very distinct form of treatment. The purpose of this study was to determine the effect of vibroacoustic therapy on low back pain management in adolescents. A total of 40 adolescents (13-18 years old) were randomly divided into two equal groups (exercise - control group, and exercise and vibroacoustic therapy - vibroacoustic group), and participated in a 3-week physiotherapy program for back pain management. The participants in both groups performed the same exercise program five times per week. The participants in the vibroacoustic group apart from exercise also received treatment on a special vibro chair set at 4-8 Hz frequency for relaxation. Music was heard through the headphones. Standard tests (Oswestry disability index and the visual analogue pain scale) to assess low back pain were used before and after the intervention to monitor changes. The intensity of low back pain significantly decreased in both groups after the intervention $(P<0.05)$, but there were no significant differences between the groups in low back pain management in adolescents.
\end{abstract}

Keywords: vibroacoustic therapy, low back pain, adolescents.

\section{Introduction}

Low back pain is a very common global health problem and a major cause of disability affecting general well-being and activity limitation. Low back pain affects people of all ages. The prevalence rate for children and adolescents is lower than that seen in adults but is on the increase $[1,2]$.

Acute low back pain is mainly treated by means of analgesics [3]. Alternative treatments include physiotherapy, electrotherapy, back schools, and spinal manipulations [4].

Vibration therapy is quite a novel adjunct to exercise that is currently being tested in sports, geriatrics, and rehabilitation $[5,6]$. Ordinary mechanical vibrating devices are used to relieve pain and induce relaxation [7]. It is recognized that specific parts of the body respond to specific frequencies. For example, the great muscles of the back are generally stimulated by frequencies in the 50-hertz range. It is also known that to achieve the same focus of sensation in a different subject or in the same subject at a different time, the frequency may have to be changed by several Hz. Vibroacoustic Therapy provides evidence of the physical effect of sound and confirms the fundamental principle that low frequencies can be relaxing [8].

The aim of this study was to assess the effect of Vibroacoustic therapy (VT) on the management of low back pain in adolescents treated in a children's hospital outpatient ward. 


\section{Methods}

\subsection{Participants}

Participants were patients from a Children's hospital. Forty adolescents (13 boys and 27 girls; mean \pm SD age: $15.38 \pm 1.55$ years) met the inclusion criteria and agreed to participate in the study. The inclusion criteria were: age between 13 and 18 years, ambulatory rehabilitation due to non-specific low back pain, written consent of the parents allowing their child to participate in the study, pain intensity not higher than moderate, no prescription of medications for pain management and no contraindications to vibration exposure (pacemaker, current kidney or gall stones, acute lower back pain, blood clot or thrombosis within the last six months, fracture or joint replacement within the past 12 months, vibration-related injuries, amputation of lower extremities other than toes, diabetes mellitus, tumours).

The participants, matched for age, were randomly divided into two groups: Control $(n=20$; performed exercise) and Vibroacoustic ( $n=20$ performed exercise and got vibroacoustic therapy).

\subsection{Intervention}

All participants from both groups participated in a 3-week (16 procedures, 30-minute exercise session every working day) physiotherapy program for low back pain management. The physiotherapy program consisted of core stabilization exercises. In addition to the trunk stabilization exercise program participants of Vibroacoustic group received 16 treatment sessions with duration of $20 \mathrm{~min}$. on a special vibro chair set at 4-8 Hz frequency. Music was heard through the headphones.

\subsection{Technical characteristics of vibroacoustic chair}

“Zen evolution" vibroacoustic armchair (Model ZK2, ZAV2, DVP3520/8, HD202 II West) consists of an armchair with a vibro device built into it (Fig. 1). Vibroacoustic Therapy transmits the pre-recorded music combined with sinusoidal low frequency sound, through a vibroacoustic chair with built-in 4 low sound subwoofers (Fig. 1). Loudspeakers were used to generate the vibrations at a 4-8 Hz frequency, and an audible sound was produced through the headphones. Headphones transmit sound with individually adjustable strength. Technical characteristics of headphones: Voltage of $220 \mathrm{~V}, \pm 20 \mathrm{~V}$; Frequency of 50-60 Hz; Power of $120 \mathrm{~W}$. Tone control: Low sounds: $\pm 10 \mathrm{~dB}$ at $100 \mathrm{~Hz}$; High sounds: $\pm 10 \mathrm{~dB}$ at $20000 \mathrm{~Hz}$, re-establishing the range of $20 \mathrm{~Hz}-20000 \mathrm{~Hz}$.

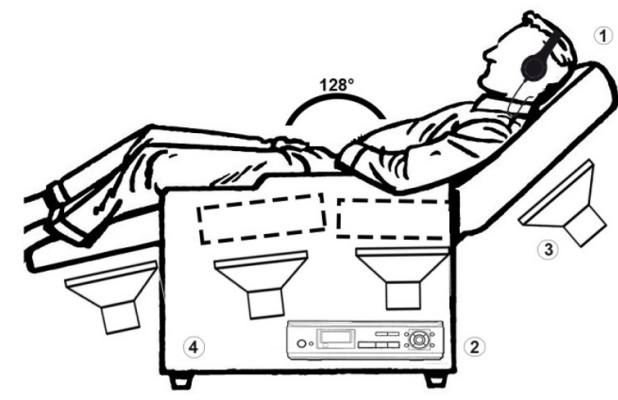

1- Headphones

2- DVD with 2 channel amplifier

3- Subwoofer svstem

Fig. 1. Vibroacoustic chair (“Zen evolution”)

The Vibroacoustic Therapy lasted for $20 \mathrm{~min}$. The patient determinate comfortable vibration level (scale on switch from 1 to 10), which was not changed during the therapy session. 


\subsection{Outcome measures}

Oswestry Low Back Pain Disability Questionnaire (Oswestry Disability Index - ODI) [9]. The purpose of this tool is to assess pain-related disability in persons with low back pain. The Oswestry Disability Index (ODI) is based on ten questions, each followed by six alternatives (A-F). Each question is to be answered by selecting one of the six alternatives, and each selected letter is evaluated by a number of points [10]: A-0; B-1; C-2; D-3; E-4; and F-5. The points are then summed up, the maximal score (50 points) indicating the poorest evaluation of function and the minimal score ( 0 points) compares to a good functional evaluation. The percentage score is calculated by applying the following formula: sum score/ $50 \times 100=$ percentage $(\%)$.

The percentage scale ranges from 0 to $100 \%$, a lower score means a lesser influence of lumbar pain on the patient's functional status. Conclusions are made based on the calculated percentage scores [11]: 0-20\% - minimal dysfunction; 21-40\% - moderate dysfunction; 41-60\% - severe dysfunction; 61-80 \% - disabled; and 81-100\% - bed mode/simulated symptoms.

Visual Analogue Pain Scale (VAS) [12]. VAS is one of the most commonly used measures of pain intensity in pain research. It may help to evaluate the pain intensity prior to and following treatment. Later the obtained data regarding the changes in pain intensity may help to evaluate the efficacy of the treatment and any changes in the patient's condition. This scale is suitable for the evaluation of back pain in scores from 1 to 10 . Weak pain - 1-3 scores; moderate pain - 4-5 scores; severe pain - 6-7 scores; very severe pain - 8-9 scores; and unbearable pain - 10 scores.

All measures were performed at baseline and after the 3-week intervention.

\subsection{Statistical analysis}

Quantitative variables were expressed as mean \pm standard deviation (SD). Differences in baseline characteristics between the two groups was assessed using Mann-Whitney $U$ test, and changes between before and after intervention - Wilcoxon test. All subjects completed the study, so no adjustments were needed for drop-outs.

Analyses were performed using SPSS version 19. The difference across groups and trials were considered statistically significant when $\mathrm{P}$ values were less than 0.05 .

\section{Results}

The results of the VAS and ODI in both groups before and after the intervention are presented in Table 1.

Table 1. Low back pain and oswestry disability index in both groups before and after the intervention

\begin{tabular}{|l|c|c|c|c|}
\hline \multirow{2}{*}{ Measurements } & \multicolumn{2}{|c|}{ Before intervention } & After the 3 weeks intervention \\
\cline { 2 - 5 } & Control group & Vibroacoustic & Control group & Vibroacoustic \\
\hline Low Back Pain & $5.3 \pm 1.78$ & $4.6 \pm 1.73$ & $2.85 \pm 1.63^{*}$ & $1.9 \pm 1.71^{*}$ \\
\hline Oswestry index & $9.25 \pm 3.35$ to & $8.75 \pm 4.54$ & $6.30 \pm 3.33^{*}$ & $6.05 \pm 3.87^{*}$ \\
\hline$*$ Difference within group is significant $(P<0.05)$ \\
\hline
\end{tabular}

After the 3-week intervention, both groups demonstrated a significant decrease in low back pain and Oswestry disability index (Fig. 2).

There were no significant differences between groups before and after the intervention in low back pain score, with both groups displaying a similar improvement post-intervention (Fig. 3 and Fig. 4). 


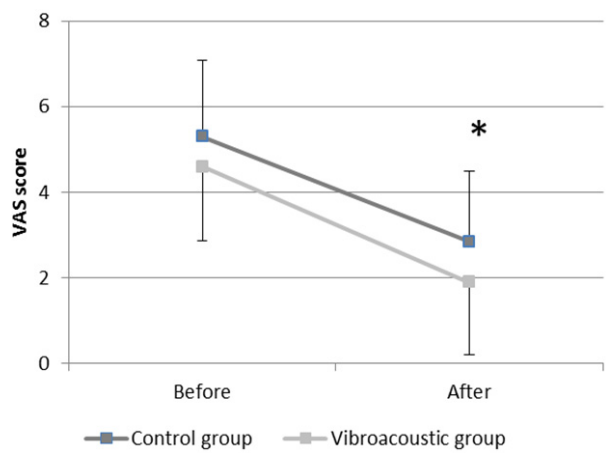

a)

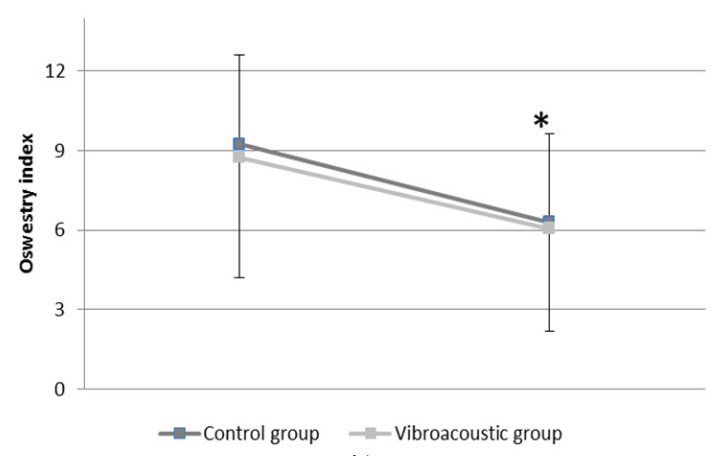

b)

Fig. 2. Results of low back pain (VAS score) and Oswestry Disability Index in adolescents before and after the intervention: a) results of low back pain (VAS score); b) results of Oswestry index; $*$ difference within groups is significant $(P<0.05)$

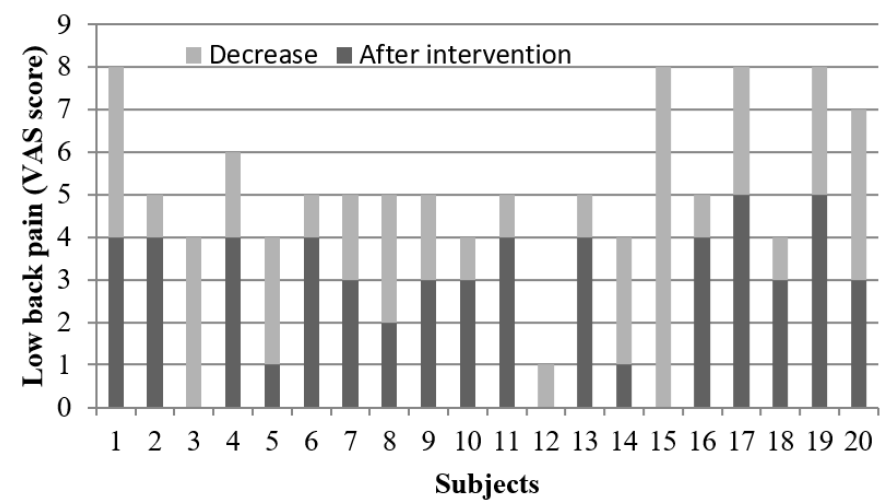

Fig. 3. Decrease of low back pain in every subject in the Control group

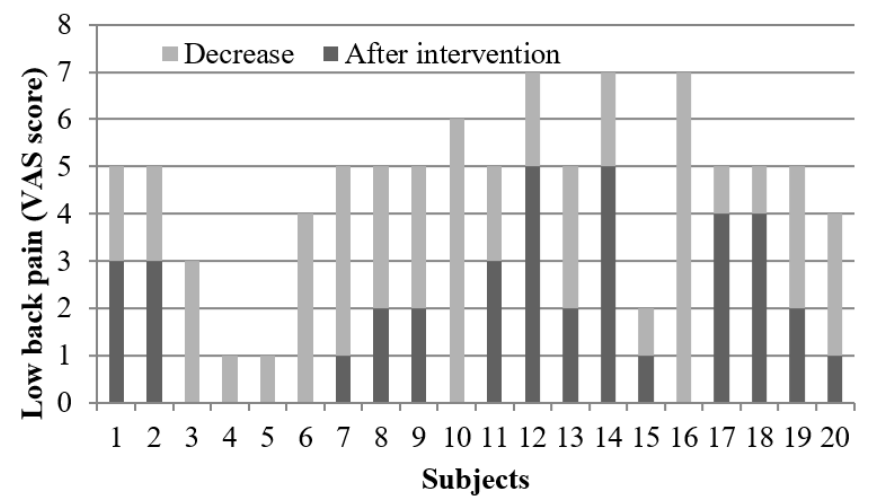

Fig. 4. Decrease of low back pain in every subject within the Vibroacoustic group

\section{Discussion}

Although vibroacoustic is not a new concept in the treatment of physical disabilities and pain, it is not a commonly used treatment tool in hospitals. The first attempts in using Vibroacoustic Therapy were conducted in Norway in 1980 by Olav Skille [14] and this method was named "low frequency sound massage". Historically vibroacoustic therapy was thought to be effective in treating different health problems $[13,14]$.

The present study investigated the potential added benefits of using Vibroacoustic Therapy as 
a supplement to a 3-week physiotherapy program for low back pain management in adolescents. The absence of individuals dropping-out of the study suggests that the vibroacoustic therapy was well tolerated. Subjects choose frequencies which fall within the range of human hearing and could result in physiological responses indicative of relaxation [8].

At the conclusion of the 3 -week intervention, significant improvement $(P<0.05)$ was noted for the control group (core stabilization exercises) and Vibroacoustic group (core stabilization exercises and Vibroacoustic Therapy) on low back pain score and Oswestry disability index.

Several studies have shown the beneficial effect of vibroacoustic therapy on pain management [7, 15-17] on anxiety [18], and even on palliative care patients [19].

Results of this study demonstrate that vibroacoustic therapy did not have statistical significance and did not influence the outcome of the patient's low back pain and disability index compared to only physiotherapy program.

The literature suggests that music reduces anxiety, decreases pain, and increases feeling of well-being [19] using this vibroacoustic method, however the desired goals of relaxation of back muscles and the decrease in low back pain were not achieved in our study. This contrasts with Patrick (1999) in which study he also used visual analogue scale and got a reduction of pain and symptoms by $53 \%$ [17].

Vibroacoustics therapy is a non-invasive, safe therapy that is stated to decrease pain, reduce anxiety, reduce the symptoms of illness and generally promotes health in many patients [20]. Although Vibroacoustic Therapy in this study did not result in any additional benefits based on our outcome measures, future studies should be done including large populations, longer period of treatment and different frequencies of vibration.

Vilma Dudoniene - scientific leader, author of the article, Lina Varniene and Tomas Aukstikalnis - main researchers, Egle Lendraitiene - responsible for statistical analysis; Justas Cerkauskas - inventor of the vibro chair, Juozas Raistenskis - organizer of research.

The authors declare that they have no competing interests.

\section{Conclusions}

The results of the present study showed that the vibroacoustic therapy in addition to a 3-week physiotherapy program of core stabilization exercises had the same effect as the core stabilization exercise program only in the management of low back pain in 13-18 years old adolescents. Both groups in the study showed significant but similar improvement in pain reduction following a 3 -week intervention. Future investigations are required to explore the potential of vibroacoustic therapy in the treatment of low back pain.

\section{Acknowledgements}

A special thanks goes to prof. Artūras Kaklauskas (Vilnius Gediminas Technical University) for the opportunity to test and evaluate vibrochair on pain management in adolescents with low back pain.

\section{References}

[1] Calvo-Muñoz I., Gómez-Conesa A., Sánchez-Meca J. Prevalence of low back pain in children and adolescents: a meta-analysis. BMC Pediatrics, 2013, p. 13-14.

[2] Kordi R., Rostami M. Low back pain in children and adolescents: an algorithmic clinical approach. Iranian Journal of Pediatrics, Vol. 21, Issue 3, 2011, p. 259-270.

[3] Staal J. B., de Bie R. A., de Vet H. C., et al. Injection therapy for subacute and chronic low back pain: an updated Cochrane review. The Spine Journal, Vol. 34, Issue 1, 2009, p. 49-59.

[4] van Tulder M. W., Koes B. W., Bouter L. M. Conservative treatment of acute and chronic nonspecific low back pain. A systematic review of randomized controlled trials of the most common interventions. The Spine Journal, Vol. 22, Issue 18, 1997, p. 2128-2156. 
[5] Russo C. R., Lauretani F., Bandinelli S., et al. High-frequency training increases muscle power in postmenopausal women. Archives of Physical Medicine and Rehabilitation, Vol. 84, Issue 12, 2003, p. 1854-1857.

[6] Dudonienė V., Šakalienė R., Švedienė L., et al. Impact of whole body vibration on balance improvement in elderly women. Journal of Vibroengineering, Vol. 15, Issue 3, 2013, p. 1112-1118.

[7] Boyd-Brewer C. Vibroacoustic therapy: sound vibrations in medicine. Alternative and Complementary Therapies, Vol. 9, Issue 5, 2003, p. 257-263.

[8] Hooper J. An introduction to vibroacoustic therapy and an examination of its place in music therapy practice. British Journal of Music Therapy, Vol. 15, Issue 2, 2001, p. 69-77.

[9] Fairbank J. C., Pynsent P. B. The Oswestry disability index. The Spine Journal, Vol. 25, Issue 22, 2000, p. 2940-2952.

[10] Kumar T., Kumar S., Nezamuddin M., et al. Efficacy of core muscle strengthening exercise in chronic low back pain patients. The Journal of Back and Musculoskeletal Rehabilitation, Vol. 28, Issue 4, 2015, p. 699-707.

[11] Shamsi M. B., Sarrafzadeh J., Jamshidi A. Comparing core stability and traditional trunk exercise on chronic low back pain patients using three functional lumbopelvic stability tests. Physiotherapy Theory and Practice, Vol. 31, Issue 2, 2015, p. 89-98.

[12] Carlsson A. M. Assessment of chronic pain. I. Aspects of the reliability and validity of the visual analogue scale. The Journal of Pain, Vol. 16, Issue 1, 1983, p. 87-101.

[13] Skille O., Wigram T., Weekes L. Vibroacoustic therapy: the therapeutic effect of low frequency sound on specific physical disorders and disabilities. British Journal of Music Therapy, Vol. 3, Issue 2, 1989, p. 6-10.

[14] Wigram A. L., Weekes L. A project evaluating the difference in therapeutic treatment between the use of low-frequency sound and music, and music alone, in reducing high muscle tone in multiply handicapped people, and oedema in mentally handicapped people. Second ISVA Symposium in Steinkjer, 1989.

[15] Boyd-Brewer C., McCaffrey R. Vibroacoustic sound therapy improves pain management and more. Holistic Nursing Practice, Vol. 18, Issue 3, 2004, p. 111-118.

[16] Chesky K. S., Michel D. E. The music vibration table (MVT): developing a technology and conceptual model for pain relief. Music Therapy Perspectives, Vol. 9, 1991, p. 32-38.

[17] Patrick G. The effects of vibroacoustic music on symptom reduction: inducing the relaxation response through good vibrations. IEE Engineering in Medicine and Biology, 1999, p. 97-100.

[18] Pratt D. A. The Effects of Vibroacoustic Therapy (VT) and Music on Anxiety in Patient Undergoing Breast Biopsy. Dissertation submitted to the Faculty of Holos University Graduate Seminary in partial fulfillment of the requirements for the degree of Doctor of theology, 2008, p. 15.

[19] Warth M., Kessler J., Kotz S., et al. Effects of vibroacoustic stimulation in music therapy for palliative care patients: a feasibility study. BMC Complementary and Alternative Medicine, Vol. 15, 1, p. 2015-436.

[20] McCaffrey R. G., Good M. The lived experience of listening to music while recovering from surgery. Journal of Holistic Nursing, Vol. 18, Issue 4, 2000, p. 378-390.

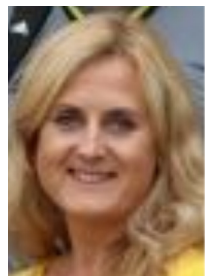

Vilma Dudoniene received her Doctoral degree in biomedical sciences at Lithuanian Sports University in 2000 with the thesis "Effect of heating and exercises on muscle function". Her current position is Assoc. Prof. at Lithuanian Sports University, research interest - effect of different physiotherapy methods on person's functioning.

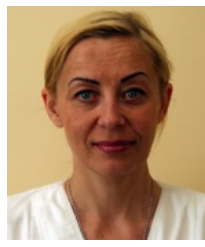

Lina Varnienė received her Master's diploma in rehabilitation with professional qualification as physiotherapist at Lithuanian Sports University in 2007. She is currently working at the Department of Rehabilitation of Vilnius University and in Children's Hospital, Affiliate of Vilnius University Hospital Santariskiu Klinikos. Her research interest is efficiency of different physiotherapy techniques. 


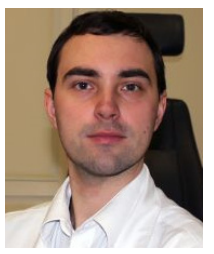

Tomas Aukštikalnis - physician at Children's Hospital, Affiliate of Vilnius University Hospital Santariskiu Klinikos (since 2013 physician certificated by UEMS PRM). Professional and research interests are rehabilitation of children with neurological and orthopedic impairments, non-medical chronic pain treatment, functional testing and rehabilitative interventions.

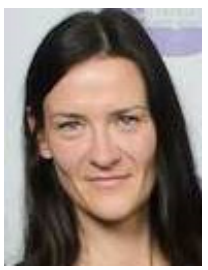

Eglè Lendraitienè received her Doctor's degree in biomedicine at the Lithuanian University of Health Sciences, Kaunas, Lithuania, in 2007. She is currently working at the Lithuanian University of Health Sciences. Her current research interests are neurological physiotherapy, different technics oh physiotherapy and their efficiency.

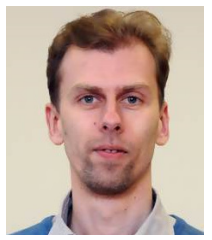

Justas Čerkauskas is a researcher at the Institute of Internet and Intelligent Technologies and a Ph.D. student in the Department for Construction Technology and Management. His work focuses on fields such as virtual reality, biometric technologies, the development of intelligent computer learning systems, e-city, the analysis of e-city systems, the development of recommendation systems, intelligent built environment, and online artificial intelligence technologies.

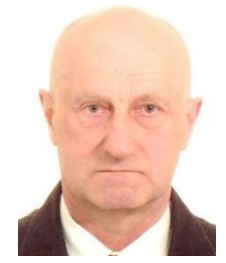

Juozas Raistenskis is a Professor at Department of Rehabilitation, Physical and Sports Medicine of Vilnius University. He is a head of Children's Hospital, Affiliate of Vilnius University Hospital Santariskiu Klinikos. His main fields of interest are children's health, alternative medicine, children's rehabilitation, and public health. 